\title{
Effect of sodium hypochlorite, chlorhexidin and EDTA on dentin microhardness
}

Sazan Sherdil Saleem**

Basam Kareem Amin*

Abstract

Background and objective: The use of chemical irrigants solution in root canal therapy is capable of altering the proportion of organic and inorganic components of root canals. The structural properties of dentin may be changed such as permeability, solubility and microhardness. The aim of this study was to evaluate the effects of root canal irrigants on the microhardness of root canal by using three types of irrigant solutions with different concentration and normal saline used as control group.

Methods: Root halves were prepared by longitudinal splitting of the roots of 56 freshly extracted caries free maxillary second premolars and embedded in autopolymerizing acrylic resin, leaving the dentin surface exposed. The root halves were randomly divided to seven groups composed of 16 samples each and treated for five minutes with one of the following irrigants: normal saline (control group), $0.2 \%$ chlorhexidin, $2 \%$ chlorhexidin, $2.5 \%$ sodium hypochlorite, $5.25 \%$, 5\% Ethylene dimetha tetra hydrate EDTA and $17 \%$ EDTA. After surface treatment, the dentin microhardness of the root samples were recorded at the mid-root level by using a vicker microhardness tester. The data were statistically analyzed by using one-way analysis of variance, followed by Duncans test with a significant difference test at $P \leq 0.05$.
\end{abstract}

Results: EDTA, sodium hypochlorite, and $2 \%$ chlorhexidin significantly decreased the microhardness of root dentin compared with controls $(P<0.05)$, while $0.2 \%$ chlorhexidin had no significant effect on the microhardness of root dentin.

Conclusion: The irrigant solutions affect the microhardness of the samples except $0.2 \%$.

Keywords: Microhardness, EDTA, Chlorhexidine gluconate, sodium hypochlorite.

\section{Introduction}

The aim of root canal treatment is to remove bacteria and debris from the root canal space. This goal is achieved by using irrigant solution. Irrigation flushes away the loose, necrotic and contaminated materials outside the canal before they are pushed deeper into the apical direction. ${ }^{1,2}$ Sodium hypochlorite $(\mathrm{NaOCl})$ has been recommended to remove the organic tissues (necrotic and vital tissues) from the root canals because of its solvent activity. Chlorhexidin (CHX) has antibacterial effect and no cytotoxicity. The different concentrations of EDTA are also used for debridement of root canal by improving the removal of smear layer because act as chelating agent. ${ }^{3,4}$ Dentin microstructure and its properties are very important in restorative dentistry. Knowledge of mechanical properties of human root canal dentin would help restorative treatment. Microhardness de-fine as the resistance to local deformation and it tests based on the induced permanent surface deformation that remains after removal of load. Hardness measurement can be correlated with the other mechanical properties such as fracture resistance. After the use of chemical irrigants, which are capable of altering the proportion of organic and inorganic components of root canals, the structural properties of dentin may be

*Department of conservative, college of dentistry, Hawler Medical University, Erbil, Iraq.

**Department of P.O.P, college of dentistry, Hawler Medical University, Erbil, Iraq. 
changed such as permeability, solubility and microhardness. Microhardness is considered as indirect evidence of mineral changes in root canal dentin; such changes may affect the adhesive properties of root canal dentin surface and sometime may decrease the strength of root and cause root fracture. ${ }^{5,6}$ Previous studies demonstrated that $\mathrm{NaOCl}$ and EDTA solutions decrease the microhardness of root dentin, while solution containing different concentration of $\mathrm{CHX}$ had varying effect on microhardnes. In the other studies, the addition of surface modifiers to the irrigants did not affect the microhardness of the dentin surface. ${ }^{2,6,7}$ This study aimed to evaluate the effects of root canal irrigants on the microhardness of root canal dentin by using these irrigant solutions with different concentration and normal saline used as control group.

\section{Methods}

\section{Samples preparation:}

Fifty six freshly extracted caries free maxillary second premolars (malposed tooth) were collected from patient between 18-25 years old of ages. At this age the pulp canals are wide and there is less possibility of pulp stone or obstruction. After removal of surrounding soft tissue and debris, the teeth were stored in $10 \%$ formalin until use. The crowns of the teeth were removed at the cementoenamel junction under water cooling. The roots were split longitudinally into the buccal and lingual halves with a low speed diamond disc and embedded in acrylic resin block, leaving the dentin surface exposed.

\section{Samples treatment}

The root halves were randomly allocated into seven groups $(n=16)$ and treated for 5 minutes with $5 \mathrm{ml}$ of the following irrigants:

Group 1: The surfaces treated with normal saline (NS)

Group 2: The surfaces treated with $5 \%$ EDTA.

Group 3: The surfaces treated with $17 \%$ EDTA.
Group 4: The surfaces treated with $2.5 \%$ $\mathrm{NaOCl}$.

Group 5: The surfaces treated with $5.25 \%$ $\mathrm{NaOCl}$.

Group 6: The surfaces treated with $0.2 \%$ $\mathrm{CHX}$.

Group 7: The surfaces treated with $2 \%$ $\mathrm{CHX}$.

After surface treatment, the samples were dried and the dentin microhardness of each sample was determined.

Determination of dentin microhardness: The dentin microhardness of the root samples was measured by using a vicker microhardness tester (Wolpert/German) at magnification of (X 250) and a depth of $(300 \mu \mathrm{m})$ from the pulp dentin interface. Three separate indentations were made by using $(500 \mathrm{~g})$ load and 10 seconds dowel time at the mid root level of root dentin samples.

\section{Statistical analysis:}

The effects of irrigant solutions on microhardness of root dentin were statistically analyzed using statistical package for the social sciences. Comparisons between experimental groups were performed by using one-way analysis of variance (ANOVA), followed by Duncan test with significant difference at $P \leq 0.05$.

\section{Results}

Descriptive statistical results concerning alterations in root canal dentin after treatment with the experimental solutions are presented in Table 1. The statistical comparison (ANOVA and Duncans test) (Table 1 and 2) revealed significant difference among groups $(P<0.05)$. The Duncans test (Table 1) indicated that $17 \%$ EDTA treatment significantly decreased the microhardness of root dentin when compared other groups and showed the lowest microhardness mean value. $5 \%$ EDTA and $5.25 \% \quad \mathrm{NaOCl}$ significantly decreased the microhardness of root dentin when compared to control, $0.2 \% \quad \mathrm{CHX}$ and $2 \% \mathrm{CHX}$ groups. However, control and $0.2 \% \mathrm{CHX}$ showed significantly lowest alteration in 
Effect of sodium hypochlorite, chlorhexidin and.......

Zanco J. Med. Sci., Vol. 20, No. (1), 2016

http://dx.doi.org/10.15218/zjms.2016.0006

microhardness value without significant difference between them.

Table 1: Mean values (VHN) standard deviations, standard errors and 95\% confidence intervals for Microhardness data

\begin{tabular}{|c|c|c|c|c|c|c|c|c|c|}
\hline \multirow[t]{2}{*}{ Groups } & \multirow[t]{2}{*}{$\mathbf{N}$} & \multirow[t]{2}{*}{ Mean } & \multirow{2}{*}{$\begin{array}{l}\text { Std. } \\
\text { Deviation }\end{array}$} & \multirow{2}{*}{$\begin{array}{l}\text { Std. } \\
\text { Error }\end{array}$} & \multicolumn{2}{|c|}{$\begin{array}{l}95 \% \text { Confidence } \\
\text { Interval for Mean }\end{array}$} & \multirow[t]{2}{*}{ Minimum } & \multirow[t]{2}{*}{ Maximum } & \multirow{2}{*}{$P$ value } \\
\hline & & & & & $\begin{array}{l}\text { Lower } \\
\text { Bound }\end{array}$ & $\begin{array}{l}\text { Upper } \\
\text { Bound }\end{array}$ & & & \\
\hline Control & 16 & $61.47 \mathrm{e}$ & 3.83146 & 1.21162 & 58.7322 & 64.2140 & 55.79 & 68.47 & \\
\hline $5 \%$ EDTA & 16 & $52.50 \mathrm{~b}$ & 2.12638 & .67242 & 50.9809 & 54.0231 & 50.20 & 55.63 & $<0.001$ \\
\hline $17 \%$ EDTA & 16 & $40.53 a$ & 1.06783 & .33768 & 39.7741 & 41.3019 & 38.52 & 41.93 & \\
\hline $2.5 \% \mathrm{NaOCl}$ & 16 & $55.61 \mathrm{c}$ & 1.51426 & .47885 & 54.5288 & 56.6952 & 52.43 & 57.43 & \\
\hline $5.25 \% \mathrm{NaOCl}$ & 16 & $52.57 \mathrm{~b}$ & 2.01631 & .63761 & 51.1292 & 54.0140 & 50.20 & 55.63 & \\
\hline $0.2 \% \mathrm{CHX}$ & 16 & $60.29 \mathrm{e}$ & 2.79163 & .88279 & 58.3006 & 62.2946 & 55.79 & 64.77 & \\
\hline $2 \%$ CHX & 16 & $57.98 \mathrm{~d}$ & 2.06765 & .65385 & 56.5099 & 59.4681 & 54.23 & 60.50 & \\
\hline Total & 112 & 54.42 & 6.94855 & .83051 & 52.7694 & 56.0830 & 38.52 & 68.47 & \\
\hline
\end{tabular}

Different alphabets show significant differences.

Table 2: ANOVA test for the effect of different irrigation solutions on the microhardness of root dentin

\begin{tabular}{llllll}
\hline & Sum of Squares & df & Mean Square & F & $P$ value \\
\hline Between Groups & 2982.560 & 6 & 497.093 & 89.754 & $<0.001$ \\
Within Groups & 348.919 & 63 & 5.538 & & \\
Total & 3331.479 & 69 & & & \\
\hline
\end{tabular}




\section{Discussion}

Chemical agents used during endodontic treatment is essential to remove the smear layer during root canal therapy and this may lead to alterations in root dentin and changes in its chemical and physical properties. The degree of mineral content and the amount of hydroxyapatite in the intertubular substance are important factors in the intrinsic hardness profile of dentin structure. Previous studies reported a positive correlation between hardness and mineral content in teeth. Consequently, the measurement of microhardness can provide indirect evidence of mineral loss or gain in dental hard tissues. ${ }^{6,8,9}$ On the other hand, decrease in the microhardness can affect the adhesion and sealing ability of the sealers to the root dentin walls. ${ }^{10,11}$ Therefore, this study was aimed to compare the effect of different root canal irrigant solutions $\mathrm{CHX}$, EDTA and $\mathrm{NaOCl}$ on microhardness of the root canal dentin was evaluated by using a Vickers hardness tester. Selection of Vickers microhardness tester over Knoop hardness tester was due to the suitability and practicality of Vickers test for evaluating surface changes of deeper dental hard tissues. Knoop hardness tester is used for superficial dentin at $0.1 \mathrm{~mm}$ rather than for deep dentin. ${ }^{10,12}$ The result of present study demonstrated that all the root canal irrigant solutions decreased dentin microhardness with the exception of saline and $0.2 \% \mathrm{CHX}$. This finding is in accordance with Saleh and Ettman, ${ }^{13}$ Sousa and Silva, ${ }^{14}$ Khedmat and Shokouhinejad ${ }^{15}$ and DaSilva et al, ${ }^{16}$ who evaluated the effect of $\mathrm{NaOCl}$ and EDTA on the microhardness of root canal dentin and reported that both solutions decreased the microhardness of root dentin but EDTA irrigation induced more reduction. The chelating action of EDTA solution induces an adverse softening potential on the calcified components of dentin, and subsequently a reduction in the microhardness was expected. The organic dissolving properties of $\mathrm{NaOCl}$ on the collagen component of dentin explain how the alternated irrigation with these solutions affects the hardness of dentin. ${ }^{10,17} \mathrm{NaOCl}$ is known to dissolve both magnesium and phosphate ions, while increasing the amount of dentinal carbonate. In addition, it was reported that $\mathrm{NaOCl}$ treatment significantly altered the $\mathrm{Ca} / \mathrm{P}$ ratio of the root dentin surface. Because the degree of dentin mineralization may affect the hardness profile of the dentin structure, changes inmineral content after $\mathrm{NaOCl}$ treatment could be responsible for changes in dentin microhardness. ${ }^{1,18}$ The current study agree with the study by Slutzky-Goldberg et al, ${ }^{18}$ Ari et al, ${ }^{19}$ and Olivei-ra et al, ${ }^{20}$ who conclude that sodium hypochlorite significantly reduces the microhardness of root canal dentin. $\mathrm{CHX}$ does not affect the microhardness of root canal dentin this agree with the finding of Ari et al, ${ }^{19}$ who conclude that $0.2 \%$ Chlorhexidine Gluconate seems to be an appropriate endodontic irrigation solutions because of its harmless effect on the microhardness of root canal dentin. The result of the current study also agrees with the finding of Oliveira et $\mathrm{al}^{20}$ who found that $\mathrm{CHX}$ significantly reduces the microhardness at a concentration of $2 \%$ and $\mathrm{CHX}$ at this concentration may alter the mineral content of the dentin. It was previously reported that $\mathrm{CHX}$ is not capable of dissolving necrotic tissues or removing the smear layer. The remaining smear layer may act as a barrier, which allows for only minimal changes in microhardness by limiting irrigant contact with dentin. In contrast, it was reported that $\mathrm{CHX}$ treatment at concentrations of $2 \%$ decreased the $\mathrm{Ca}$ and $P$ levels and the microhardness of root dentin. It was suggested that this change in microhardness might be dependent on the concentration of $\mathrm{CHX}{ }^{1,20}$

\section{Conclusion}

The softening effect of chemical irrigants on dentinal walls could be of clinical benefit because it permits rapid preparation and facilitates the negotiation of root canals 
http://dx.doi.org/10.15218/zjms.2016.0006

with small dimension. However, these alterations may affect the adhesion profile of sealers to treated dentin surfaces. The results of this study demonstrated that EDTA and $\mathrm{NaOCl}$ significantly decrease the microhardness of the root dentin surface. In addition, EDTA caused a larger reduction of microhardness than $\mathrm{NaOCl}$ and $\mathrm{CHX}$.

\section{Conflicts of interest}

The authors report no conflicts of interest.

\section{References}

1. West JD, Roane JB. Cleaning and shaping the root canal system. In: Cohen S, Burns RC, eds. Pathways of the Pulp, 7th ed. St Louis: CV Mosby; 1998. P. 203-57.

2. Aslantas EE, Buzoglu HD, Altundasar E, Serper A. Effect of EDTA, Sodium Hypochlorite, and Chlorhexidine Gluconate with or without Surface Modifiers on Dentin Microhardness. J Endod 2014; 40 (6):876-9.

3. Jeansonne MJ, White RR. A comparison of $2.0 \%$ of chlorhexidine gluconate and $5.25 \%$ sodium hypochloride as antimicrobial endodontic irrigants. J Endod 1994; 20:276-8.

4. Hulsmann M, Heckendorff M, Lennon A. Chelating agents in root canal treatment: mode of action and indications for their use. Int Endod J 2003; 36:810-30.

5. Panighi M, G'Sell C. Influence of calcium concentration on the dentine wettability by an adhesive. J Biomed Mater Res 1992; 26:1081-9.

6. Cruz-Filho AM, Sousa-Neto MD, Savioli RN. Effect of chelating solutions on the microhardness of root canal lumen dentin. J Endod 2011; 37:358-62.

7. Akcay I, Sen BH. The effect of surfactant addition to EDTA on microhardness of root dentin. J Endod 2012; 38:704-7.

8. Arends J, Bosch JJ. Demineralization and remineralization evaluation techniques. J Dent Res 1992; 71:924-8.

9. Panighi M, G'Sell C. Influence of calcium concentration on the dentine wettability by an adhesive. J Biomed Mater Res 1992; 26:1081-9.

10. Kandil HE, Labib AH, Alhadainy HA. Effect of different irrigant solutions on microhardness and smear layer removal of root canal dentin. Tan Dent J 2014; 11(1):1-11.

11. Akcay I, Sen BH. The Effect of Surfactant Addition to EDTA on Microhardness of Root Dentin. J Enodod 2012; 38 (5):704-7.

12. AL-Ashou WO. The Effects of Two Root Canal Irrigants and Different Instruments on Dentin Microhardness ( In Vitro Study). Al - Rafidain Dent J 2011; 1(1):63-70.
13. Saleh AA and Etman WM. Effect of endodontic irrigant solutions on microhardness of root canals dentine. J Dent 1999; 27:43-8.

14. Sousa SMG, Silva TL. Demineralization effect of EDTA, EGTA, CDTA and citric acid on root dentin: a comparative study. Braz Oral Res 2005; 19:188-92.

15. Khedmat S, Shokouhinejad N. Comparison of the efficacy of three chelating agents in smear layer removal. J Endod 2008; 34:599-602.

16. Dasilva LA, Sanguino AC, Rocha CT, Leonardo MR, Silva RA. Scanning electron microscopic preliminary study of the efficacy of smear clear and EDTAfor smear layer removal after root canal instrumentation in permanent teeth. $\mathrm{J}$ Endod 2008; 34:1541-4.

17. Zhang K, Kim YK, Cadenaro M. Effects of different exposure times and concentrations of sodium hypochlorite/ethylenediaminetetraacetic acid on the structural integrity of mineralized dentin. J Endod 2010; 36:105-9.

18. Slutzky- Goldberg I, Maree M, Liberman R, Heling I. Effect of Sodium Hypoch-lorite on Dentin Microhardness J Endod. 2004; 30:880-2.

19. Ari $\mathrm{H}$, Erdemir A, Belli $\mathrm{S}$. Evaluation of the Effect of Endodontic Irrigation So-lution on the Microhardness and Rough-ness of Root Canal Dentin. J Endod 2004; 30:792-7.

20. Oliveira L, Carvahlo C, Nunes W, Valera M, Camargo C, Jorge A. Effect of Chlorhexidin and Sodium Hypochlorite of Root Canal Dentin. Oral Surg Oral Med Oral Pathol Oral Radiol Endod 2007; 104:125-33. 